\title{
The S\&P500 index effect reconsidered: evidence from overnight and intraday stock price performance and volume
}

Article

Accepted Version

Kappou, K., Brooks, C. and Ward, C. (2010) The S\&P500 index effect reconsidered: evidence from overnight and intraday stock price performance and volume. Journal of Banking \& Finance, 34 (1). pp. 116-126. ISSN 0378-4266 doi: https://doi.org/10.1016/j.jbankfin.2009.07.008 Available at https://centaur.reading.ac.uk/18666/

It is advisable to refer to the publisher's version if you intend to cite from the work. See Guidance on citing.

To link to this article DOI: http://dx.doi.org/10.1016/j.jbankfin.2009.07.008

Publisher: Elsevier

All outputs in CentAUR are protected by Intellectual Property Rights law, including copyright law. Copyright and IPR is retained by the creators or other copyright holders. Terms and conditions for use of this material are defined in the End User Agreement.

www.reading.ac.uk/centaur 
Central Archive at the University of Reading

Reading's research outputs online 
NOTICE: this is the author's version of a work that was accepted for publication in the Journal of Banking and Finance. Changes resulting from the publishing process, such as peer review, editing, corrections, structural formatting, and other quality control mechanisms may not be reflected in this document. Changes may have been made to this work since it was submitted for publication. A definitive version was subsequently published in the Journal of Banking and Finance, 34.1 (2010),

DOI: $10.1016 /$ j.jbankfin.2009.07.008 


\title{
The S\&P500 index effect reconsidered: Evidence from overnight and intraday stock price performance and volume
}

Konstantina Kappou ${ }^{\mathrm{a}}$, Chris Brooks ${ }^{\mathrm{a}, *}$, and Charles Ward ${ }^{\mathrm{a}}$

${ }^{a}$ ICMA Centre, University of Reading, UK.

This Version: July 2009

\begin{abstract}
This study focuses on S\&P500 inclusions and deletions, examining the impact of potential overnight price adjustment after the announcement of an S\&P500 index change. We find evidence of a significant overnight price change that diminishes the returns available to speculators although there are still profits available from the first day after announcement until a few days after the actual event. More importantly, observing the tick-by-tick stock price performance and volume effects on the key days during the event window for the first time, we find evidence of consistent trading patterns during trading hours. A separate analysis of NASDAQ and NYSE listed stocks allows for a detailed examination of the price and volume effect at an intra-day level. We find that index funds appear to cluster their rebalancing activities near to and after the close on the event date, suggesting that they are more concerned with tracking error than profit.
\end{abstract}

JEL classification: G10; G14

Keywords: Index effect; S\&P500; Market efficiency; Price pressure

* Corresponding author. Tel.: +44 118378 7809; fax: +44 1189314741.

E-mail addresses: Konstantina.Kappou@googlemail.com (K.Kappou), C.Brooks@rdg.ac.uk (C. Brooks), C.W.R.Ward@icmacentre.ac.uk (C. Ward).

Acknowledgements: We are grateful to two anonymous referees for useful comments that considerably re-shaped and improved this paper. We would also like to thank S\&P Corporation for providing information on the announcement and effective dates of S\&P500 inclusions. We are grateful to Carol Alexander, Ron Bird, Peter Corvi, Anca Dimitriu, Alfonso Dufour, Alan Goodacre, Apostolos Katsaris, Salih Neftci, Jacques Pezier, and Paul Woolley for their comments. This work was also improved by helpful comments from the Trading Team at Credit Suisse. The usual disclaimer applies. This paper was originally submitted to Professor Giorgio Szego on 20 June 2007 and was revised twice prior to submission through EES. 


\section{Introduction}

Over the last 20 years, index funds have become extremely popular, with total worldwide explicitly indexed assets estimated to exceed $\$ 1$ trillion. When "trackers" follow a benchmark index, their investment decisions are not based on fundamental analysis. Instead, they make the necessary portfolio adjustments only to reduce tracking error, which ensures that such funds will prefer index member stocks to non-members. Thus the deletion of an existing member-firm from a widely followed benchmark has a significant implication for fund managers. For pure index trackers, the only reason, apart from changing cash flows, for trading stocks will be index composition reviews.

The "index effect" refers to the price pressure that is observed when a stock is added to or deleted from an index. If the index is widely tracked, then profits can be made by buying (selling) the shares of the added (deleted) firm ahead of index funds and selling (buying) them at a later stage, when index fund demand (supply) is satisfied. The more money is tied to the index, the more index portfolio managers will be involved in trading the underlying stocks around index recomposition. Index trackers ensure that demand will increase for added stocks and will reduce for deleted stocks. For many years, "buying additions and selling deletions" has been a lucrative strategy for investors not involved in index tracking. ${ }^{1}$

This study examines the impact of potential overnight price adjustment after the announcement of an S\&P500 index addition as well as the impact on the prices and volumes of the stocks on a tick-

\footnotetext{
${ }^{1}$ Academic research has supported this statement for more than 20 years. The abnormal return reported between announcement and event of an index change has ranged between 3\%-8\% depending on the time period studied (Harris and Gurel, 1986; Beneish and Whaley, 1996; Malkiel and Radisich, 2001; Chen, Noronha and Singal, 2004). Standard and Poor's analysts have also reported evidence of significant abnormal returns during periods of recomposition of the main indices (S\&P 500, S\&P MidCap400 and S\&P SmallCap 600) - see Bos (2000).
} 
by-tick basis. A separate analysis is conducted for additions and deletions and also for NASDAQ listed versus NYSE listed stocks. Previous studies have mainly concentrated on close-to-close abnormal returns and showed that there is a significant price increase between the close on the announcement day and the close on the day after. However, the purchase of the added stock cannot be made at the close of trading on the announcement day because the information is released to the market after the close. The first trading opportunity arises in the morning of the first day after announcement, when the stock usually opens at a considerable price increase, resulting in lower actual trading profits; our study investigates this issue in detail.

The following analysis differs from previous studies in four important areas. First, the results involve not only close-to-close abnormal returns but also overnight and open-to-close returns. Second, the tick-by-tick stock price performances and trading volumes of the added stocks are examined for the first time for the years 1999 and 2000. This analysis enables us to provide a more detailed picture of the objectives and actions of index fund managers and arbitrageurs. Third, NYSE and NASDAQ samples are examined separately to determine the impact of trading venue on the index effect. ${ }^{2}$ Finally, we make use of a more recent and longer run of data on index additions than was available in previous studies.

The remainder of this study is organized as follows. Section two provides a brief description of the major stock selection criteria and the announcement policies of the Standard and Poor's Index Committee. Section three presents a brief summary of previous relevant studies associated with S\&P500 index changes and the prevailing hypotheses that lie behind the companies' post-event

\footnotetext{
${ }^{2}$ This separation may be particularly important where trading volumes are concerned since there is evidence that volumes are considerably over-estimated on the NASDAQ, although in a complex way, so that a simple adjustment for comparability is not possible - see Anderson and Dyl (2005).
} 
performance. Section four examines the stock performance after addition by using overnight and open-to close data and section five provides results using tick-by-tick abnormal returns. Section six presents an analysis of the index effect at the intra-day level and section seven examines the intra-day index affect of a deletions sample. Section eight concludes.

\section{Index tracking and the S\&P500}

The S\&P500 is a value-weighted index that reflects the market value of all 500 component US stocks relative to a particular base period. The selection and management of the index is determined by the Standard and Poor's Index Committee. Changes in index composition are mainly caused by member companies effectively ceasing to exist in their current form through mergers, takeovers, restructuring or bankruptcies. According to a statement by Standard and Poor's, candidate firms are "monitored carefully and the criteria for inclusion are highly stringent". After screening candidate companies, an S\&P500 Replacement Pool is created that contains at least 10 companies. The prevailing company from this Pool is chosen whenever a new entry to the index is required following the deletion of another company. The selection process for S\&P500 membership does not simply refer to a typical quantitative ranking system based on market capitalisation. Therefore, it is difficult for institutional investors and fund managers to anticipate the changes. This is in contrast with the procedures that operate for most other major indices. In general, but not exclusively, S\&P member companies have the largest market value in their sector and are chosen to represent their industry in the US market. The selection process 
entails an examination of the firm's trading activity, such as public float ${ }^{3}$ and turnover ratios, to ensure high liquidity and to reduce the probability of deviations from the "fair" stock price.

Standard and Poor's changed their announcement policy twice - in September 1976 and more recently in October 1989. The latter change was made in order to alleviate the price pressure on the announcement date that occurred prior to this when index inclusion took place immediately the day after announcement. Changes are now pre-announced an average of five days before the event. The period from the announcement date to the effective date offers time for institutional investors and index fund managers to adjust their holdings. The announcement, which takes place after the market close, reveals the name of the firm that will be added (deleted) and the exact date that the event will take place. ${ }^{4}$ In some instances, however, only the name of the firm and not the exact date of the event is announced.

\section{Previous literature}

The period during which a change in index composition occurs constitutes a useful laboratory for testing the Efficient Market Hypothesis (EMH). According to the semi-strong form of the EMH, the market's historical knowledge of abnormal returns for index additions (deletions) will drive the security's price up (down) to its expected addition (deletion)-day value on the day after the announcement (Cusick, 2002). The profits from buying the stock on the day after the announcement and selling it on the effective date should be fully eliminated and the change in the security’s price should happen overnight.

\footnotetext{
${ }^{3}$ In March 2004, Standard and Poor's announced that it would convert all major U.S. indices to a float-adjusted basis and in September 2004, it released details of the methodology used for the free-float calculation. In March 2005, S\&P500 became half-float adjusted and in September 2005, full-float adjusted.

${ }^{4}$ We would like to thank Milvia Luckenbach and Srikant Dash from Standard and Poor's Corporation for providing information concerning the new announcement policy.
} 
Numerous studies show that the index effect results in stock price behavior during the event period that appears inconsistent with the EMH. Consequently, a number of hypotheses have been proposed to justify this performance. These are the Price Pressure Hypothesis (see Harris and Gurel, 1986; Wooridge and Ghosh, 1986; Malkiel and Radisich, 2001), the Imperfect Substitutes/Downward-Sloping Demand Curve for Stocks Hypothesis (Schleifer, 1986; Denis et al., 2003), the Liquidity Cost Hypothesis (Mikkelson and Partch, 1985; Amihud and Mendelson, 1986), the Information Content/Index Member Certification Hypothesis (Jacques, 1988; Dhillon and Johnson, 1991), and the Market Segmentation/Investor Recognition Hypothesis (Chen et al., 2004). Their main differences concern whether the stock price or volume change is temporary or permanent after the event, what kind of information is revealed by an addition or deletion, and what are the main issues for stock and investor behavior. While the number of papers examining whether these hypotheses receive empirical support is large, with the exception of three, all consider only close-to-close returns. Such research arguably presents a misleading picture of the profitability of trading on changes in index composition since these profits cannot be realized by investors.

Beneish and Whaley $(1996,1997)$ are the first to examine close-to-open returns to measure the extent of overnight performance that is consistent with market efficiency using index inclusions under both the old and new regimes. The overnight pressure under the old policy was expected to be larger since there was no interval between announcement and event. The major part of the abnormal close-to-close return of added stocks under the old announcement policy was caused overnight $(4.37 \%)$ and the open-to-close abnormal return of the following day was $-0.62 \%$ leaving no profitable trading opportunities. Under the new announcement policy, however, an 
abnormal return that is significant but substantially smaller in magnitude occurs overnight $(2.46 \%)$ with an insignificant (positive) open-to-close return the next day $(0.6 \%)$.

Open-to-close returns are also examined by Cusick (2002), who finds evidence of an increase in market efficiency through time, and a decrease in the trading profit available to arbitrageurs who buy additions and sell deletions. By using the size of the overnight abnormal return from the close on the announcement date until the following morning as a proxy for investors' interest, he shows that the potential trading profits available have decreased over time. His main conclusion is that investors' interest will outweigh the increase in indexing and the available trading profit will diminish through time.

No previous studies on the S\&P500 index effect employ tick-by-tick data. The methodology used in this work to obtain intra-day abnormal returns is similar to that of Wood, McInish and Ord (1985), who examine the return characteristics of trades at the micro level, although not relating specifically to the index effect. In the case of S\&P500 inclusions, new information is released overnight and increased trading volume is expected at the beginning of the day after announcement. According to Easley and O'Hara (1992), bid-ask spreads should widen upon the occurrence of large block transactions to reflect the uncertainty of the future price equilibrium and therefore, high standard deviations of intraday returns should also be expected. However, inclusions are events that require significant index fund rebalancing, and specialists as well as market makers can afford to tighten their spreads in the short run due to increased volumes (Beneish and Whaley, 1996). In any case, the U-shaped pattern of return variation may not be pronounced since significant trading activity is likely to occur throughout the whole trading day 
and the evidence of increased liquidity found in previous studies (Edmister, Graham and Pirie, 1996 and Erwin and Miller, 1998) will not adversely affect trading costs.

\section{The overnight and open-to-close effect}

\subsection{Data and methodology}

Stock opening and closing prices are obtained from Thomson Datastream. There are insufficient data for the benchmark opening prices before the year 1993 and therefore, firms that were added to the S\&P500 before that year are not examined; the final sample contains 266 stock additions to the S\&P500 for the period 1993-2002. Of these stocks, 188 are traded on the NYSE and 78 on the NASDAQ. The abnormal open-to-close return (OTC) for each firm is obtained by subtracting the benchmark return from the open-to-close performance of the stock. The same approach is repeated for calculating close-to-close abnormal returns (CTC) from the announcement day (AD) close until AD+1 close. The overnight performance is then derived by subtracting the open-toclose performance from the close-to-close performance:

$$
\begin{aligned}
& A R_{C T C i t}=R_{C T C i t}-R_{C T C m t} \\
& A \text { RoTCit }=\text { RoTCit }- \text { RoTCmt } \\
& O V R_{i t}=A R_{C T C i t}-A R_{\text {OTCit }}
\end{aligned}
$$

where, in the case of the first day after the S\&P press release, $R_{C T C i t}$ and $R_{C T C m t}$ are the close-toclose returns between $\mathrm{AD}$ and $\mathrm{AD}+1$ for the stock and the S\&P500 respectively, $R_{\text {OTCit }}$ and $R_{\text {OTCm }}$ are the open-to-close returns between $\mathrm{AD}+1$ open and $\mathrm{AD}+1$ close for the stock and the benchmark respectively, $A R_{C T C i t}, A R_{O T C i t}$ are the abnormal close-to-close and open-to-close returns for each stock respectively, and $O V R_{i t}$ is the overnight (non-tradable) abnormal return between $\mathrm{AD}$ close and $\mathrm{AD}+1$ open for each firm. This method is repeated for the key days during 
the event window until the day after the effective index change $(E D+1)$. Returns are constructed in their continuously compounded form (i.e. log price relatives) throughout this study.

\subsection{Results}

\subsubsection{The whole sample}

Table 1 presents the close-to-close, open-to-close and overnight data between announcement date and effective date with their corresponding $t$-statistics. On the day of announcement (AD), the open-to-close return is insignificant, indicating no pre-emptive trading of the future index change. Moreover, despite the $4.06 \%$ abnormal return from the close of trading on AD to the close on $\mathrm{AD}+1$, it is clear that there are no trading opportunities on $\mathrm{AD}+1$ because the open to close return is significantly negative at the $1 \%$ level $(-0.83 \%)$. The overnight performance averages $4.89 \%$ on $\mathrm{AD}+1$ (significantly different from zero at the $1 \%$ level), indicating that market makers have very positive expectations concerning added firms. The overnight performance is also positive and significant every day up to and including $A D+5$ (except for $A D+2$ where it is positive but not significant) as well as on ED; thereafter, the returns on ED+1 and ED+2 both represent statistically significant reversals.

Table 2 repeats the above analysis but the sample is now divided into two different sub-periods, for the years 1993-1997 and 1998-2002. Additions to and deletions from the S\&P500 have become more frequent over the more recent period, and therefore the sample of firms added to the index during the latter period is larger (88 firms in the earlier sub-period and 178 firms in the later one). The firms added during the first sub-period experience an overnight price increase of $3.89 \%$ after the close on $\mathrm{AD}$ and a further marginal and insignificant price increase of $0.02 \%$ between $\mathrm{AD}+1$ open and $\mathrm{AD}+1$ close. By contrast, in the more recent sub-period, the overnight 
return between $\mathrm{AD}$ close and $\mathrm{AD}+1$ open is $5.38 \%$, with a highly significant negative return of $-1.25 \%$ from the open until the close the day after $(\mathrm{AD}+1)$.

The evening of the ED is the last point where the S\&P500 has its old composition, and index fund managers will have already started rebalancing their portfolios (the new composition and divisor adjustment of the S\&P500 index are based on ED closing prices). The close-to-close abnormal return between ED-1 and ED is significantly different from zero when considering the whole sample or either sub-period. However, the ED open-to-close return remains insignificantly different from zero for the recent period sub-sample, showing that index fund demand does not appear to drive price patterns. It is also worth noting that in the more recent sub-period, the AD+1 close-to-close price increase is higher, although the ED close-to-close price increase is lower. In other words, the abnormal return premium has shifted towards the announcement date. This can be attributed to a potential increase in the number of arbitrageurs through time (since the "S\&P Game" has become more widely known and the number and financial power of hedge funds has grown enormously) who may be trying to make a profit by buying the stock ahead of index funds. It could be also attributed to an increase in market efficiency, ${ }^{5}$ where participants are aware of the positive addition effect and thus drive prices up immediately after the announcement date instead of on the event date.

To conclude, according to the above findings, even if the AD+1 close-to-close abnormal return is eliminated, there are still some profitable trading opportunities beyond $\mathrm{AD}+1$ until the date of the

\footnotetext{
${ }^{5}$ The t-statistic for the difference across the two sub-samples in the overnight performance between AD close and $\mathrm{AD}+1$ open is statistically significant and higher for the recent sub-sample.
} 
actual event. The results thus far are consistent with those of Beneish and Whaley (1996 and 2002) and Cusick (2002).

\subsubsection{The overnight effect: NASDAQ listed versus NYSE listed stocks}

The NYSE and NASDAQ exchanges are very different in the way that they operate. The former is a specialist market, where all trades occur in a physical place (the NYSE trading floor), whereas the latter is a dealer market that is based on a telecommunications network. Christie and Schultz (1994), and Bessembinder and Kaufman (1997) have shown the prevalence of the NYSE as a more efficient and less costly exchange. The exchanges also differ in the types of the securities that are traded. Stocks listed on the NYSE exchange are typically "blue chips" - i.e., established companies, whereas stocks listed on the NASDAQ are usually considered to possess significant growth opportunities but with higher levels of risk.

An important advantage of the NYSE is that the market is centralized and the specialist can more easily handle any liquidity problems. On the other hand, the NASDAQ exchange is relatively decentralized and has greater market depth due to the increased competition among dealers and to the direct trading that takes place between market participants in the event of demand or supply shocks. LaPlante and Muscarella (1997) showed that the NYSE provides greater liquidity to the market than the NASDAQ in the case of large block trades. Chung et al. (2008) also suggest that specialists make faster quote adjustments towards equilibrium spreads on the NYSE than they do on the NASDAQ. Inferences about the differences between the two exchanges can be more accurately made when comparing open-to-close data, where actual trading is taking place, rather than the close-to-close data used in previous studies. 
Table 3 presents the average daily performance of NASDAQ and NYSE listed stocks separately. Even if on a close-to-close basis, the exchanges seem to produce different average abnormal stock returns on the first trading day after the announcement, and most of the difference occurs overnight. In particular, the level of overnight abnormal return for the NASDAQ sample between $\mathrm{AD}$ close and $\mathrm{AD}+1$ open is $6.65 \%$ on average, relative to $4.20 \%$ for the NYSE sample. This difference is significant at the $1 \%$ level (t-statistic $=4.63)$. It would thus appear that investors perceive a NASDAQ stock inclusion to be more positive news than the addition of a NYSE stock. The exchange effect is confirmed by the open-to-close data, showing an advantage of the specialist market. This result echoes that of Elliott and Warr (2003), who use daily data to investigate differences in the index effect across the two markets. NYSE stocks experience a positive open-to-close abnormal return of only $0.48 \%$ relative to a figure of $1.05 \%$ for NASDAQ stocks on the event day. This discrepancy could arise from differential levels of transaction costs as well as differing levels of liquidity of NASDAQ versus NYSE added stocks. ${ }^{6}$ The overnight abnormal return between ED close and ED+1 open is significantly negative for both NASDAQ and NYSE stocks $(-1.15 \%$ and $-0.4 \%$ respectively) and statistically different for the two samples (t-statistic $=2.69$, with the NASDAQ sub-sample realising a larger price reversal).

\section{The tick-by-tick performance of the stocks that are added to the S\&P500 index}

\subsection{Data and methodology: The trade and quote (TAQ) database}

The $T A Q$ database contains intraday transactions data for all securities listed on the New York Stock Exchange (NYSE), the NASDAQ National Market System (NMS) as well as the American

\footnotetext{
${ }^{6}$ In fact, spreads on NASDAQ stocks are comparable with those of NYSE stocks for most of the trading day, averaging 7-10bps (basis points), but NYSE spreads widen considerably to over 100 basis points at the close, while those of the NASDAQ remain at around 10bps. The issue of transactions costs will be discussed in detail in Section VI.
} 
Stock Exchange (AMEX). This analysis uses the reported trades on each day within the event window for firms added to or deleted from the S\&P500, but tick-by-tick data are only employed for the years 1999 and 2000. The final sample consists of 91 added firms (with deletions discussed in Section 7). In estimating tick-by-tick abnormal returns, the S\&P500 index cannot be used directly as a benchmark because intraday index changes are significantly less frequent than the intraday changes of the added stocks. The closest substitute for the S\&P500 index that is traded as a stock and is also very liquid is the "SPIDER" (SPY) fund. ${ }^{7}$ All the trades recorded on each day are collected from the TAQ Database for the sample of firms and for the SPY.

Each firm that was added to the index differs from others in the sample in terms of liquidity and the number of trades recorded. To allow for this, we adopt a reference time in seconds from 09.30 to 16.00 . The recorded trades (one series for the prices and one series for the number of shares) for each firm are then allocated according to their reported times. ${ }^{8}$ The interval selected for analysis is five minutes and therefore, the intraday price and volume performance between 09.30 and 16.00 for each stock has 78 observations per day. In order to compress the reference time in seconds into five-minute intervals, in the case of firms with more than one reported trade per five minutes, the sum of the reported quantities of shares over that interval is used as the number of shares traded, and the last reported price is used as the price over that interval. ${ }^{9}$ In the case where the firm has not reported any trades over a five-minute interval, the sum of the number of shares

\footnotetext{
${ }^{7}$ The SPDR (SPY) fund is an ETF (Exchange Traded Fund) that holds all the components of the S\&P500 index.

${ }^{8}$ The more liquid firms cover every second during the reference time and in some cases, there is more than one trade per second which occurred at the same price. To overcome this, for those particular seconds, the total number of shares traded at the same price is reported as one trade. On the other hand, the less liquid firms have failed to report a trade for some seconds of the day and there are gaps in the reference time. However, this is not a problem, since the final chosen time interval is longer than a single second and consequently, all firms report at least one trade per time interval.

${ }^{9}$ In the same way, stock markets record the last price as the closing price of the day and not the weighted average price of the trades throughout the whole day.
} 
traded in that interval is zero and the price for that interval is the same as that of the previous one. The same approach is employed to obtain tick-by-tick prices of the SPIDER (SPY) index fund. Logarithmic returns are then obtained for each stock and for the SPY by taking the differences of the log prices over five-minute intervals, consistent with the method of Wood, McInish and Ord (1985). Abnormal returns are then derived by taking the difference between the stock return and the benchmark return for all 78 observations each day:

$$
A R_{i, j}=R_{i, j}-R_{S P Y, j}
$$

where $R_{i}$ and $R_{S P Y}$ are the interval returns during the trading hours for each stock $i$ and for the SPY respectively and $A R_{i, j}$ is the abnormal stock return for each interval $j$.

In order to measure the intraday trading volume during each day within the event window, the number of shares traded per five-minute interval is expressed as a percentage of the total shares traded each day for each firm to allow a comparison among firms of different liquidities. These percentages are then averaged across firms for each interval and are free of any bias that might have occurred due to the differences in the total absolute trading volumes of the stocks. This approach may reveal the timing of index fund rebalancing.

\subsection{Results}

\subsubsection{Intraday firm performance on the announcement date $(A D)$}

Figure 1 presents the cumulative abnormal performance (lines in the graph) and trading volume (bars in the graph) of the average added stock at 5-minute intervals on the date of announcement (AD). It can be seen that the overall open-to-close return for the sample of 91 firms is not more that $0.3 \%$. On the morning of the announcement date, there is no information revealed to the

market about the forthcoming S\&P500 index change, and thus price and volume behavior should 
not be driven by this event. Indeed, there is no particular trend in the average tick-by-tick performance of the stocks, and prices may be driven only by the corresponding market tick-bytick trend.

To check whether there is any anticipation of the S\&P press release (that will be posted after the close of trading), we also show the volumes over the trading day in Figure 1. For a typical trading day, a higher volume is expected over the first few minutes after the market opening as well as over the last few minutes before the market close and usually, intraday volumes trace out a "smile pattern" (Wood, McInish and Ord, 1985). The average volume observed over the last five minutes of the $\mathrm{AD}$, expressed as a percentage of the total daily volume, is high relative to the rest of the day. Investors who were actually capable of buying the added stock before the AD close due to this potential leakage could enjoy a highly significant abnormal return until the next day's close. Those who did not buy the stock by AD close will have to suffer the huge overnight price increase and buy the next day $(\mathrm{AD}+1)$ at a higher price.

\subsubsection{Intraday firm performance on the first day after announcement $(A D+1)$}

Since the average stock price reverses during the day (see Table 1), it is worth checking whether there is an optimal time to buy the stock, i.e. when the lowest price level occurs on average. Figure 2 presents the tick-by-tick cumulative performance and trading volume of the average added stock on the first day after announcement. It can be seen that the price experiences a continuous negative trend, losing part of the overnight price increase. Under the assumption that arbitrageurs and other market participants have realized that the price drops monotonically during $\mathrm{AD}+1$, they should wait and buy the stock at the market close. However, according to the volume levels presented in Figure 2, it is evident that high trading activity occurs at the opening price. 
This is reasonable given the overnight price change of almost 5\% (reported in Section 4), an increase which is statistically significant and therefore, market participants may assume a reversal within the day and start selling the stock short at the opening.

Figure 2 also shows how the total daily volume is allocated to the five-minute intervals between 09.30 and 16.00 on $\mathrm{AD}+1$. Indeed, there is selling pressure at the market open and during the first half hour, because volume figures are at their highest levels relative to total daily trading, and the price decreases. The stock price of the firm that will soon be added to the index seems to partially lose its significant overnight increase during the first day after the revision announcement. In Section 4, it was shown that the overall open-to-close return for that day is significant. The buy side of these trades may be provided by participants who aim to hold the added stock over the long run. The best time to buy the stock is a few minutes before the close, when the price is at its lowest level. However, since the stock opens at a considerably higher level than that of the previous close, one could enhance the tradable return by short selling the stock at the open on $\mathrm{AD}+1$, then buying it back again at the close of trading when it hits its lowest level, and finally taking a long position in the stock until the event date (ED).

To complete the AD+1 intraday analysis, we examine firms listed on the NASDAQ and NYSE exchanges separately. On the first day after announcement, the cumulative abnormal intraday performance of NASDAQ listed stocks is slightly worse than that of the NYSE listed stocks. The pattern observed is, however, the same (Figure 3), and there is no obvious exchange effect. This difference, especially towards the close of the trading day, may be attributed to the fact that NASDAQ listed stocks have stronger overnight performances than stocks listed on the NYSE (as 
reported in Section 4), and therefore the $\mathrm{AD}+1$ price reversal is more for the former than the latter.

\subsubsection{Intraday firm performance on the event date (ED)}

The date where the change in the S\&P500 re-composition becomes effective is the most important one in terms of index fund rebalancing. The change takes place after the close of trading on ED and therefore, index fund managers have to complete their purchases as close to the stock's closing price as possible if they wish to minimize their tracking errors. If they postpone part of their investment in the added stock until next day's morning, then they bear the risk of realizing a substantial tracking error, since the overnight price change may be considerable.

Figure 4 presents the tick-by-tick performance and trading volume of the average added stock on the event date (ED) until 18:30. The graph shows that the stock price falls during the day until around lunchtime, but closes at a positive level. There is no apparent buying pressure until 12.00, but after that time, the price has a positive trend until the close, and becomes volatile over the last hour. The stock price reaches its highest level (which is marginally up) at the market close. There are two possible explanations for this result. The first is that index funds might have started their purchases earlier by choosing to potentially enhance their portfolio returns at the possible expense of tracking error. The second explanation is that the market is no longer adding value to the stock, since it rallied from the date of announcement until the event and hence, the open-toclose return on the ED is close to zero. Index fund managers can now buy from arbitrageurs without upwardly affecting the price. 
The trading volume on that date is also of great interest. Figure 4 confirms that index funds are completing their purchases a few minutes before and after the close. The volume reported over the first five minutes after the close, expressed as a percentage of the total volume for that day, is almost $20 \%$. It is worth noting that the volume figures are very smooth throughout the day and that trading at the market opening is no heavier than usual. Volume figures become significantly high only for the last two intervals before the close and the first two after. Taking into account that overall trading volume is 16 times higher than that of a typical day, the numbers become even more extreme. There is strong evidence that most index funds are waiting to buy the added stock as close to 16.00 as possible, and hence that they are most concerned with tracking error.

When we separate the sample appropriately, we find that the NYSE and NASDAQ sub-samples behave differently. As expected, the NASDAQ stocks' prices are driven up by more than $1.5 \%$ on an open-to-close basis, while NYSE firms close down 1\%. The performance of the NYSE firms is not even affected by the increased volume during the last ten minutes and the average return remains at negative levels (relative to the market opening) throughout the event day (Figure 5). The tick-by-tick analysis therefore confirms that from an arbitrageur's perspective, NASDAQ stocks might be more profitable.

The event date is the last profitable day for long non-index trackers who are trading the added stocks, since the close-to-close returns reported after that day are significantly negative. Not only is the price pressure exhausted by the event date, but there are three consecutive and significant close-to-close price reversals on ED+1, ED+2 and ED+3. These reversals can be exploited by selling the stock short, a strategy that will be explained in detail in the following section. 


\subsubsection{Intraday firm performance after the event $(E D+1, E D+2$, and $E D+3)$}

On the first day after the event, the average added firm experiences a continuous price drop. The volumes at the beginning of the day are high, perhaps indicating that index fund rebalancing may still be occurring or that arbitrageurs are continuing to unwind their positions. However, the price does not seem to be positively affected by index fund demand. Figure 6 presents the cumulative intraday firm performance on the first day after the event, in conjunction with the volumes that occurred at each interval. Over the first ten minutes of the trading day, almost $9 \%$ of the total trading occurs. The exchange effect, on the other hand, appears irrelevant on that date and hence the analysis is not presented here.

The close-to-close abnormal return remains significant and marginally negative on ED+2 and ED+3, as can be seen from Table 1 . The added stocks behave differently across the NYSE and NASDAQ samples. However, this difference does not allow us to infer firm conclusions about further index fund trading behavior and hence it is not reported. ${ }^{10}$ In addition, beyond ED+3, the performance of the stock depends mostly on the corresponding overall market performance and the price patterns start to look similar to those reported in Figure 1 where AD is examined.

\section{An analysis of the intra-day index effect}

This section will determine the profits that are available from trading the added stocks, using the 266 firms added to the S\&P500 index over the years 1993-2002, and taking into account close-toclose, open-to-close, overnight and abnormal returns. Table 4 presents a summary of the gross and net profits that can be made during S\&P500 index addition events based on the abnormal

\footnotetext{
${ }^{10}$ Results for the tick-by-tick stock price and volume performance for the second and third day after the event, as well as other analysis described but not presented, are available from the authors upon request.
} 
return levels that were found in Section 4. The timing of buying and selling stocks will be based on the high frequency analysis presented in Section 5. The strategy involves three basic steps: First, being short the added stock from the open of the first day after the announcement until the close, since the tick by tick results showed that the lowest price level was at the market close. Second, the reversal of the position until the close of the event date and third, being short the stock again from the close of the event date until the close of the third day after the event. Our approach to testing the profitability of trading index additions is similar in spirit to, but slightly more complex than, that employed by Beneish and Whaley (1997) and Cusick (2002). By calculating the abnormal returns of newly included stocks over the event period, we obtain a percentage profit identical to that which would follow from buying the stock and simultaneously short selling the index (through futures or exchange traded funds). In our case, the strategy also involves buying the index and short selling the stock at the appropriate points during the event window.

The net figures presented in Table 4 allow for transactions costs. In general, S\&P500 stocks are very liquid, and in particular, during S\&P500 rebalancing periods where a great deal of index fund trading occurs, spreads become even tighter as liquidity spikes on those days (Edmister, Graham and Pirie, 1996). The findings of Erwin and Miller (1998) also suggest a significant decrease in both relative and absolute bid-ask spreads. Beneish and Whaley (1996) argue that this decrease should be expected since the specialist will be comfortable in reducing the spread given that trading volumes during the event are very high, and also, index funds will act to reduce spreads as they are likely to place limit orders. 
Our strategy involves transactions at the open and the close of the market, but the quotes reported in the TAQ database for these times differ significantly from those reported throughout the remainder of the day. For example, the bid ask spread as a percentage of the mid-price is $45 \mathrm{bps}$ on average if calculated at the close, and only $12 \mathrm{bps}$ if calculated during the day. ${ }^{11}$ Our strategy involves 3 round-trip transactions (sell + buy, buy + sell, sell + buy). The additional costs of short selling will vary from one stock to another, although they can be as low as 20-40bps per year. ${ }^{12}$

The trading costs in Table 4 are calculated individually for each firm based on the bid-ask spreads for the stocks at the times the proposed trades would have taken place and on the costs of the off-setting positions in the SPIDER at that time, and these costs are then subtracted from the gross returns for each firm to obtain net returns. These net returns are then averaged across the stocks to form an overall net profitability for the strategy. The mean difference test reported assesses whether the average net returns are significantly different from zero after allowing for transactions costs calculated in this way.

From Table 4, it can be seen that the first part of the tradable abnormal return is $-0.31 \%$ after transactions costs, which is just significant at the $10 \%$ level. ${ }^{13}$ The cumulative abnormal return

\footnotetext{
${ }^{11}$ The fall in bid-ask spreads through the day from the market open is related to the clustering of prices at round numbers towards the start of the day - see Ohta (2006).

${ }^{12}$ We do not have data on the separate costs of short selling for each firm over our sample period and so, following many other studies such as that by $\mathrm{Li}$ et al. (2008), these costs are not considered. Hence the proposed trading strategy and the profits it is able to generate will be limited to some extent by short sale costs and constraints.

${ }^{13}$ The number of days between announcement and event varies among the added firms, averaging 5.06 days. We now describe how the cumulative abnormal return between $\mathrm{AD}+1$ and $\mathrm{ED}$ is calculated, since there are two possible methods. The first is to calculate the cumulative return and divide it by the number of days in the interval from $\mathrm{AD}+1$ to $\mathrm{ED}$, to obtain the average rest-of-the-window daily abnormal return for each stock. Then this average daily abnormal return should be multiplied by the average interval length of 4.06 days (because AD+1 is not included). The sum of all these returns divided by the number of additions will give the final estimate of the average cumulative abnormal return. The second and simpler way to calculate an average return is to take the sum of the cumulative realised returns for each firm from $\mathrm{AD}+1$ close to $\mathrm{ED}$ close and divide it by the number of firms. This method does
} 
from $\mathrm{AD}+1$ close to $\mathrm{ED}$ close that constitutes the second part of the strategy is $3.13 \%$ net and is highly significant. Finally, a short position in the stock from ED close until ED+3 close will result in another highly significant net profit of $1.66 \%$. The total tradable net profit is $5.1 \%$ on average. Our abnormal return (gross trading profit) is slightly larger than that reported by Beneish and Whaley (1997) of $5.45 \%$ because we allow for short selling of the stock at some points during the event window, whereas they assume that a long stock - short index strategy prevails throughout. ${ }^{14,15}$ It is also worth mentioning that the negative intraday return of AD+1 represents the price correction after the large overnight performance from $\mathrm{AD}$ close to $\mathrm{AD}+1$ open. The positive overnight return (non-tradable) between $\mathrm{AD}$ close and $\mathrm{AD}+1$ open tended to increase through time, as did the price reversal on the next day ( $\mathrm{AD}+1$ open-to-close). Therefore, the profits captured from selling the stock at the AD+1 opening and buying it back at the $A D+1$ close would also have increased through time.

\section{The intra-day index effect for deleted stocks}

There are relatively few studies regarding the stocks deleted from the S\&P500 index because of the difficulty in constructing a pure sample which is unbiased with respect to other events. For example, if a firm is about to declare bankruptcy, it will eventually need to be deleted from the index, but its performance thereafter will be affected by two factors - a deletion effect and a bankruptcy effect. The same applies to takeovers and mergers which are similar firm-specific

\footnotetext{
not account for the differences in the interval lengths. However, when both methods are employed, the results are not significantly different and therefore, only the results from the simpler (second) method are reported.

${ }^{14}$ Their sample periods are 1989-1995 and 1989-1999 respectively compared with the period 1993-2002 used in this study, and this difference may also partially explain the variation in results.

${ }^{15}$ The "up tick" short selling rule that formerly applied to US securities was abolished in July 2007 although it applied during our sample period.
} 
events. ${ }^{16}$ Studies that examine the impact of deletions are small both in number and in sample size investigated: Goetzman and Garry (1986), 7 deletions; Harris and Gurel (1986), 13 deletions; and Lynch and Mendenhall (1997), 15 deletions. The broad consensus of this literature is that the index effect is even more pronounced and more permanent for deletions than additions. This study now repeats the above analysis to investigate the intra-day price and volume effects around S\&P500 index composition changes on a sample of 19 "pure" deletions (not resulting from mergers, takeovers or bankruptcy) during the years 1999-2000.

The close to close abnormal return of the average deleted stock on the first day after announcement is $-7.43 \%$ (Table 5) on a close-to-close basis, although almost all of this occurs overnight. As the table shows, significant returns take place on $\mathrm{AD}+1$ and $\mathrm{ED}$. On day ED+2, there is a price reversal of $2.02 \%$ (on a close to close basis), which is marginally significant. We now present the intraday performance of the deletions sample on the key days in the event window. To obtain our tick by tick results, we use the same methodology as for the additions sample. Due to the limited number of firms, results for days following AD+2 but before the effective date will not be presented. We focus mainly on the $\mathrm{AD}$, which may reveal whether there is any evidence of anticipation of the announcement, $\mathrm{AD}+1$, where information is first released to the market, ED, where index funds should act to match the closing price of the deleted stock at 16.00, and ED+1, where the S\&P500 is first trading under its new composition.

\footnotetext{
${ }^{16}$ See Dutta and Jog (2009) and the references therein for a very recent discussion of the impact of mergers and acquisitions on stock prices.
} 


\subsection{Intraday price and volume performance on the announcement date}

On the announcement date, the average deleted stock experiences a negative intraday return of $-1.69 \%$. There is no clear evidence of anticipation of the event. The volume figures are smileshaped, indicating no intensive trading at any point during the day apart from at the opening and the close, a pattern which is common during a typical trading day for any stock. ${ }^{17}$

\subsection{Intraday price and volume performance on $A D+1$}

The stocks experience an average intraday (open to close) return of $-0.44 \%$, which is much smaller in magnitude than the overnight price change of $-6.99 \%$ and gives a total close to close return of $-7.43 \%$. Interestingly, almost all of the price fall during the trading day occurs with the first hour. Trading volumes are quite high during the first half an hour and then they stabilise for the rest of the day.

\subsection{Intraday price and volume performance on the effective date (ED) and on $E D+1$}

The most important result is the performance on the event date, at the close of which the S\&P500 changes composition. As Figure 7 shows, the stock price is volatile until the early afternoon when it trends downwards. By the close, the price has fallen by 3.93\% on average. As for the additions sample, the volume figures confirm that index funds wait until the close to sell the deleted stock. They appear unwilling to sell at an earlier stage, even if the price continues to fall. The maximum volume occurs around 16.00 , and this interval represents $35 \%$ of the total daily volume. In this figure, we also report volume until 18.30, which indicates evidence of significant after market hours trading or late reporting; nothing like this degree of after hours trading occurs on any other day during the event period.

\footnotetext{
${ }^{17}$ The results for this date are not shown but are available from the authors on request.
} 
During the first day where the S\&P actually trades in its new composition (ED+1), volumes for the newly deleted stocks return to their normal U-shapes, apart from increased trading by around $10 \%$ of the daily volume during the first 10 minutes. This could potentially relate to further index fund rebalancing that was not completed at the previous day's close. The average cumulative abnormal return rebounds, albeit very modestly ( $+0.05 \%$ over the whole day). ${ }^{18}$

\section{Conclusions}

The first part of this study disaggregates close-to-close abnormal returns into overnight and opento-close abnormal returns, showing that the close-to-close positive effect observed one day after the announcement of addition cannot be traded. However, profitable trading opportunities occur between the first day after announcement and the date of the actual event. The overnight price change seems to have increased over time, indicating an improvement in the level of market efficiency and a decrease in the profits available to arbitrageurs. In addition, the event date abnormal return caused mainly by index fund rebalancing has diminished over time, because most of the positive effect of being added to the S\&P500 index is reflected in the stock price in advance of the actual event.

The second part of this study examines the tick-by-tick performance of the firms that were added to the S\&P500 index over the years 1999-2000. To summarize the main findings of this analysis, the intraday stock price movements on $\mathrm{AD}$ appear to be random because information about the future index change has not been released to the market at that time. However, a relatively high volume is observed over the last five minutes of this trading day, indicating a potential leakage of information before the S\&P press release. During the trading hours of the first day after

\footnotetext{
${ }^{18}$ The results for this date are not shown but are available from the authors on request.
} 
announcement $(\mathrm{AD}+1)$, the stock experiences a price drop without reversing at all, a behavior perhaps best explained by an overshoot in the overnight price increase that occurred between AD close and $\mathrm{AD}+1$ open.

It is also worth noting the huge trading volume that occurs over the last ten minutes on the event date, which constitutes the last possible opportunity for index fund managers to rebalance their portfolios before the change becomes effective. This abnormal volume level provides evidence that most index funds seek to rebalance their portfolios as close to 16.00 as possible, and that they are concerned with tracking error. This finding is in contrast to the parting conjecture of Beneish and Whaley (1997), who suggest that index funds are rebalancing increasingly early after the announcement as they become more mindful of the price impacts of arbitrageurs. However, this increase in volume is not accompanied by a price increase, perhaps showing that other market participants, especially arbitrageurs, are unwinding their long positions in the added stock. Therefore, there is enough supply to satisfy index fund demand. After the event date, there is no further price pressure and the stock price drops significantly on both an open-to-close and an overnight basis.

This study also examines a sample of pure deletions using intra-day data, with the key findings mirroring those of the additions. While there is a fall in the price of to-be-deleted stocks following the announcement, most of this occurs overnight between $\mathrm{AD}$ and $\mathrm{AD}+1$ and hence is not tradable. There is a further large price fall on the effective day, with most of the day's trading volume happening around the close. 
From the tick-by-tick analysis, the optimal strategy for trading the added stock is to sell it short on $\mathrm{AD}+1$ at the market open and to buy it back at the close. At the same time, a further long position in the stock should be taken at $\mathrm{AD}+1$ close until the close of ED. Finally, a further short position should be taken in the stock between ED close and ED+3 close. The profits from these trades are all statistically significant and total almost $7 \%$ in gross terms and over 5\% after transactions costs. Numerous researchers have documented, based on daily price series, a perceived reduction over time in the index effect as an increased number of investors try to take advantage of it. ${ }^{19}$ We argue that this masks the profits that are available to arbitrageurs who are willing to trade on an intra-daily basis. While index funds persist in favoring accurate tracking over profitability, arbitrageurs will continue to benefit.

\footnotetext{
${ }^{19}$ Ding et al. (2009) show that the flow of capital into hedge funds has depressed absolute returns, as an increasing amount of money has chased a limited number of arbitrage opportunities.
} 


\section{References}

Amihud, Y., Mendelson, H., 1986. Asset pricing and the bid-ask spread. Journal of Financial Economics 17, 223-249.

Anderson, A-M., Dyl, E.A., 2005. Market structure and trading volume. Journal of Financial Research 28, 115-131.

Beneish, M., Whaley, R., 1996. An anatomy of the "S\&P game": The effects of changing the rules. Journal of Finance 51, 1909-1930.

Beneish, M., Whaley, R., 1997. A scorecard from the S\&P game: Can I play? Journal of Portfolio Management 23, 16-23.

Beneish, M., Whaley, R., 2002. S\&P500 index replacements: A new game in town. Journal of Portfolio Management 29, 51-60.

Bessembinder, H., Kaufman, H., 1997. A comparison of trade execution costs for NYSE and NASDAQ listed stocks. Journal of Financial and Quantitative Analysis 32, 287-310.

Bos, R., 2000. Event study: Quantifying the effect of being added to an S\&P index. Standard and Poor's Corporation Report, September.

Chen, H., Noronha, G., Singal, V., 2004. The price response to the S\&P 500 additions and deletions: Evidence of asymmetry and a new explanation. Journal of Finance 59, 1901-1929.

Christie, W., Schultz, P., 1994. Why do NASDAQ market makers avoid odd-eighth quotes? Journal of Finance 49, 1813-1840.

Chung, K.H., Chuwonganant, C., Jiang, J., 2008. The dynamics of quote adjustments. Journal of Banking and Finance 32, 2390-2400.

Cusick, P., 2002. Price effects of addition or deletion from the Standard and Poor's 500 index: Evidence of increasing market efficiency. Financial Markets, Institutions and Instruments 11, 349-383.

Denis, D., McConnell, J., Ovtchinnikov, A., Yu, Y., 2003. S\&P500 index additions and earning expectations. Journal of Finance 58, 1821-1840.

Dhillon, U., Johnson, H., 1991. Changes in the S\&P500 list. Journal of Business 64, 75-85.

Ding, B., Shawky, H.A., Tian, J., 2009. Liquidity shocks and the relative performance of hedge fund strategies. Journal of Banking and Finance 33, 883-891.

Dutta, S., Jog, V., 2009. The long-term performance of acquiring firms: A re-examination of an anomaly. Journal of Banking and Finance 33, 1400-1412. 
Easley, D., O'Hara, M., 1992. Time and the process of security price adjustment. Journal of Finance 47, 577-604.

Edmister, R., Graham, S., Pirie, W., 1996. Trading cost expectations: Evidence from S\&P500 index replacement stock announcements. Journal of Economics and Finance 20, 75-85.

Elliot, W.B., Warr, R.S., 2003. Price Pressure on the NYSE and NASDAQ: Evidence from S\&P500 index changes. Financial Management 32, 85-99.

Erwin, G., Miller, J., 1998. The liquidity effects associated with addition of a stock to the S\&P500 index: Evidence from bid/ask spreads. The Financial Review 33, 131-146.

Harris, L., Gurel, E., 1986. Price and volume effects associated with changes in the S\&P500 list: New evidence for the existence of price pressures. Journal of Finance 41, 815-829.

Jacques, W., 1988. The S\&P500 membership anomaly, or would you join this club? Financial Analysts Journal 44, 73-75.

LaPlante, M., Muscarella, C., 1997. Do institutions receive comparable execution in the NYSE and NASDAQ markets? A transaction study of block trades. Journal of Financial Economics 45, 97-134.

Li, X., Miffre, J., Brooks, C., O’Sullivan, N., 2008. Momentum profits and time-varying unsystematic risk, Journal of Banking and Finance 32, 541-558.

Malkiel, B., Radisich, A., 2001. The growth of index funds and the pricing of equity securities. Journal of Portfolio Management 27, 9-21.

Mikkelson, H., Partch, M., 1985. Stock price effects and costs of secondary distributions. Journal of Financial Economics 14, 165-194.

Ohta, W., 2006. An analysis of the intraday patterns in price clustering on the Tokyo Stock Exchange. Journal of Banking and Finance 20, 1023-1039.

Shleifer, A., 1986. Do demand curves for stocks slope down? Journal of Finance 41, 579-590.

Woolridge, R., Ghosh, C., 1986. Institutional trading and security prices: The case of changes in the composition of the S\&P500 index. Journal of Financial Research 9, 13-24.

Wood, R., McInish, T., Ord, K., 1985. An investigation of transactions data for NYSE stocks. Journal of Finance 40, 723-739. 
Table 1: Close-to-close, open-to-close and overnight average daily firm performance between AD and ED+3, 1993-2002

\begin{tabular}{|c|c|c|c|c|c|c|c|c|c|c|}
\hline Days & AD & AD+1 & $\mathrm{AD}+2$ & $\mathbf{A D}+3$ & $\mathrm{AD}+4$ & $\mathrm{AD}+5$ & ED & ED+1 & ED+2 & ED+3 \\
\hline \multicolumn{11}{|c|}{ Close-to-close } \\
\hline $\mathbf{A R}$ & $0.40 \%$ & $4.06 \%$ & $0.33 \%$ & $0.60 \%$ & $0.60 \%$ & $0.59 \%$ & $2.18 \%$ & $-0.96 \%$ & $-0.52 \%$ & $-0.78 \%$ \\
\hline t-stat & 1.67 & 16.30 & 1.66 & 2.48 & 2.36 & 1.41 & 6.57 & -4.05 & -2.64 & -3.62 \\
\hline \multicolumn{11}{|c|}{ Open-to-Close } \\
\hline $\mathbf{A R}$ & $0.12 \%$ & $-0.83 \%$ & $0.19 \%$ & $0.20 \%$ & $0.22 \%$ & $0.00 \%$ & $0.64 \%$ & $-0.36 \%$ & $-0.32 \%$ & $-0.62 \%$ \\
\hline t-stat & 0.68 & -4.50 & 1.05 & 0.92 & 0.91 & 0.01 & 2.39 & -1.96 & -1.78 & -3.22 \\
\hline \multicolumn{11}{|c|}{ Overnight } \\
\hline $\mathbf{A R}$ & $0.28 \%$ & $4.89 \%$ & $0.14 \%$ & $0.40 \%$ & $0.38 \%$ & $0.59 \%$ & $1.54 \%$ & $-0.60 \%$ & $-0.20 \%$ & $-0.16 \%$ \\
\hline t-stat & 1.98 & 19.69 & 1.30 & 2.56 & 3.42 & 2.98 & 7.79 & -4.70 & -2.59 & -1.47 \\
\hline
\end{tabular}

Notes: Figures in bold denote statistics that are significant at the 5\% level or better.

Table 2: Close-to-close, open-to-close and overnight average daily firm performance between AD and ED+1 over two different sub-periods

Panel A: 1993-1997

\begin{tabular}{|c|c|c|c|c|c|c|c|c|}
\hline Days & AD & AD+1 & $\mathrm{AD}+2$ & $\mathrm{AD}+\mathbf{3}$ & $\mathrm{AD}+4$ & $\mathrm{AD}+5$ & ED & ED+1 \\
\hline \multicolumn{9}{|c|}{ Close-to-close } \\
\hline $\mathbf{A R}$ & $-0.05 \%$ & $3.91 \%$ & $0.41 \%$ & $0.03 \%$ & $0.27 \%$ & $0.60 \%$ & $3.10 \%$ & $-0.79 \%$ \\
\hline t-stat & -0.21 & 10.74 & 1.75 & 0.11 & 1.18 & 1.36 & 6.51 & -3.45 \\
\hline \multicolumn{9}{|c|}{ Open-to-Close } \\
\hline $\mathbf{A R}$ & $0.02 \%$ & $0.02 \%$ & $0.16 \%$ & $0.10 \%$ & $0.11 \%$ & $0.38 \%$ & $1.49 \%$ & $-0.37 \%$ \\
\hline t-stat & 0.09 & 0.07 & 0.71 & 0.40 & 0.42 & 1.06 & 4.40 & -1.74 \\
\hline \multicolumn{9}{|c|}{ Overnight } \\
\hline $\mathbf{A R}$ & $-0.07 \%$ & $3.89 \%$ & $0.25 \%$ & $-0.07 \%$ & $0.16 \%$ & $0.22 \%$ & $1.61 \%$ & $-0.42 \%$ \\
\hline t-stat & -0.81 & 12.58 & 2.21 & -0.79 & 0.79 & 0.74 & 4.13 & -3.67 \\
\hline \multicolumn{9}{|c|}{ Panel B: 1998-2002 } \\
\hline Days & AD & AD+1 & $\mathbf{A D}+2$ & $\mathbf{A D}+\mathbf{3}$ & $\mathrm{AD}+4$ & AD+5 & ED & ED+1 \\
\hline \multicolumn{9}{|c|}{ Close-to-close } \\
\hline $\mathbf{A R}$ & $0.62 \%$ & $4.13 \%$ & $0.28 \%$ & $0.89 \%$ & $0.84 \%$ & $0.59 \%$ & $1.73 \%$ & $-1.04 \%$ \\
\hline t-stat & 1.85 & 12.69 & 1.05 & 2.60 & 2.07 & 1.02 & 4.00 & -3.11 \\
\hline \multicolumn{9}{|c|}{ Open-to-Close } \\
\hline $\mathbf{A R}$ & $0.17 \%$ & $-1.25 \%$ & $0.20 \%$ & $0.25 \%$ & $0.31 \%$ & $-0.17 \%$ & $0.23 \%$ & $-0.36 \%$ \\
\hline t-stat & 0.71 & -5.07 & 0.82 & 0.83 & 0.81 & -0.29 & 0.63 & -1.41 \\
\hline \multicolumn{9}{|c|}{ Overnight } \\
\hline $\mathbf{A R}$ & $0.45 \%$ & $5.38 \%$ & $0.08 \%$ & $0.64 \%$ & $0.53 \%$ & $0.76 \%$ & $1.50 \%$ & $-0.68 \%$ \\
\hline t-stat & 2.21 & 16.27 & 0.57 & 3.10 & 3.75 & 2.98 & 6.67 & -3.77 \\
\hline
\end{tabular}

Notes: Figures in bold denote statistics that are significant at the $5 \%$ level or better. 
Table 3: Close-to-close, open-to-close and overnight average daily firm performance between AD and ED+1 for NASDAQ and NYSE listed stocks, 1993-2002

Panel A: NASDAQ Stocks

\begin{tabular}{|c|c|c|c|c|c|c|c|c|}
\hline Days & AD & AD+1 & $\mathrm{AD}+2$ & $\mathrm{AD}+\mathbf{3}$ & $\mathrm{AD}+4$ & $\mathrm{AD}+5$ & ED & ED+1 \\
\hline \multicolumn{9}{|c|}{ Close-to-close } \\
\hline $\mathbf{A R}$ & $0.00 \%$ & $4.70 \%$ & $0.13 \%$ & $1.17 \%$ & $1.94 \%$ & $1.24 \%$ & $3.53 \%$ & $-1.48 \%$ \\
\hline t-stat & 0.00 & 8.47 & 0.33 & 1.99 & 2.88 & 1.46 & 4.23 & -2.16 \\
\hline \multicolumn{9}{|c|}{ Open-to-Close } \\
\hline $\mathbf{A R}$ & $-0.28 \%$ & $-1.95 \%$ & $0.17 \%$ & $-0.09 \%$ & $1.34 \%$ & $-0.10 \%$ & $1.05 \%$ & $-0.33 \%$ \\
\hline t-stat & -0.70 & -5.28 & 0.46 & -0.16 & 2.17 & -0.10 & 1.61 & -0.70 \\
\hline \multicolumn{9}{|c|}{ Overnight } \\
\hline $\mathbf{A R}$ & $0.28 \%$ & $6.65 \%$ & $-0.04 \%$ & $1.26 \%$ & $0.60 \%$ & $1.34 \%$ & $2.48 \%$ & $-1.15 \%$ \\
\hline t-stat & 1.45 & 12.24 & -0.16 & 2.86 & 2.35 & 2.99 & 5.55 & -3.16 \\
\hline \multicolumn{9}{|c|}{ Panel B: NYSE Stocks } \\
\hline Days & AD & $\mathrm{AD}+1$ & AD+2 & $\mathbf{A D}+\mathbf{3}$ & $\mathrm{AD}+4$ & $\mathrm{AD}+5$ & ED & ED+1 \\
\hline \multicolumn{9}{|c|}{ Close-to-close } \\
\hline $\mathbf{A R}$ & $0.55 \%$ & $3.86 \%$ & $0.42 \%$ & $0.37 \%$ & $0.09 \%$ & $0.22 \%$ & $1.65 \%$ & $-0.77 \%$ \\
\hline t-stat & 1.97 & 14.41 & 1.80 & 1.41 & 0.38 & 0.46 & 5.11 & -4.03 \\
\hline \multicolumn{9}{|c|}{ Open-to-Close } \\
\hline $\mathbf{A R}$ & $0.27 \%$ & $-0.34 \%$ & $0.20 \%$ & $0.26 \%$ & $-0.21 \%$ & $-0.04 \%$ & $0.48 \%$ & $-0.37 \%$ \\
\hline t-stat & 1.47 & -1.70 & 0.93 & 1.19 & -0.89 & -0.10 & 1.73 & -2.07 \\
\hline \multicolumn{9}{|c|}{ Overnight } \\
\hline $\mathbf{A R}$ & $0.28 \%$ & $4.20 \%$ & $0.22 \%$ & $0.11 \%$ & $0.32 \%$ & $0.26 \%$ & $1.17 \%$ & $-0.40 \%$ \\
\hline t-stat & 1.51 & 16.45 & 2.23 & 0.61 & 2.45 & 1.34 & 5.61 & -3.98 \\
\hline
\end{tabular}

Notes: Figures in bold denote statistics that are significant at the $5 \%$ level or better.

Table 4: Gross and net profits from trading index inclusions, 1993-2002

\begin{tabular}{lcccc}
\hline \hline & AD+1 open-to-close & AD+1 to ED close-to-close & ED to ED+3 close-to-close & Total \\
\hline \hline Gross return & $-0.83 \%$ & $3.75 \%$ & $-2.26 \%$ & $6.84 \%$ \\
Trading Costs & $0.52 \%$ & $0.62 \%$ & $0.60 \%$ & $1.74 \%$ \\
Net Return & $-0.31 \%$ & $3.13 \%$ & $-1.66 \%$ & $5.10 \%$ \\
\hline \hline \multicolumn{2}{c}{ Mean Difference Test $\left(\mathrm{H}_{0}:\right.$ net return $\left.=0\right)$} & $\mathbf{6 . 8 3}(0.0000)$ \\
\hline \hline t-statistic (p-value) & $-1.67(0.0956)$ & $\mathbf{5 . 9 3}(0.0000)$ & $\mathbf{- 3 . 8 9}(0.0001)$ & $\mathbf{6}$ \\
\hline \hline
\end{tabular}

Table 5: Close-to-close, open-to-close and overnight average daily firm performance between $\mathrm{AD}$ and $\mathrm{ED}+3$ for deletions

\begin{tabular}{|c|c|c|c|c|c|c|c|c|c|c|}
\hline Days & AD & $\mathrm{AD}+1$ & $\mathrm{AD}+2$ & $\mathrm{AD}+3$ & $\mathrm{AD}+4$ & $\mathrm{AD}+5$ & ED & ED+1 & ED+2 & ED+3 \\
\hline \multicolumn{11}{|c|}{ Close-to-close } \\
\hline $\mathbf{A R}$ & $-2.45 \%$ & $-7.43 \%$ & $-2.10 \%$ & $-0.96 \%$ & $-1.02 \%$ & $2.01 \%$ & $-3.86 \%$ & $1.10 \%$ & $2.02 \%$ & $-1.05 \%$ \\
\hline t-stat & -0.85 & -7.23 & -1.93 & -0.60 & -1.68 & 0.24 & -1.96 & 0.74 & 1.62 & -0.74 \\
\hline \multicolumn{11}{|c|}{ Open-to-Close } \\
\hline $\mathbf{A R}$ & $-1.69 \%$ & $-0.44 \%$ & $-2.57 \%$ & $-1.57 \%$ & $-1.37 \%$ & $4.00 \%$ & $-3.93 \%$ & $0.05 \%$ & $1.37 \%$ & $-1.43 \%$ \\
\hline t-stat & -0.63 & -0.63 & -2.24 & -1.13 & -1.92 & 0.59 & -2.23 & 0.03 & 1.26 & -1.17 \\
\hline \multicolumn{11}{|c|}{ Overnight } \\
\hline $\mathbf{A R}$ & $-0.76 \%$ & $-6.99 \%$ & $0.47 \%$ & $0.61 \%$ & $0.35 \%$ & $-1.99 \%$ & $0.07 \%$ & $1.05 \%$ & $0.65 \%$ & $0.38 \%$ \\
\hline t-stat & -1.02 & -6.95 & 1.19 & 1.86 & 1.03 & -1.30 & 0.05 & 0.98 & 1.27 & 0.42 \\
\hline
\end{tabular}


Figure 1: Tick-by-tick cumulative abnormal performance and number of shares traded over each five-minute interval expressed as a percentage of the total daily volume of the average added stock on AD

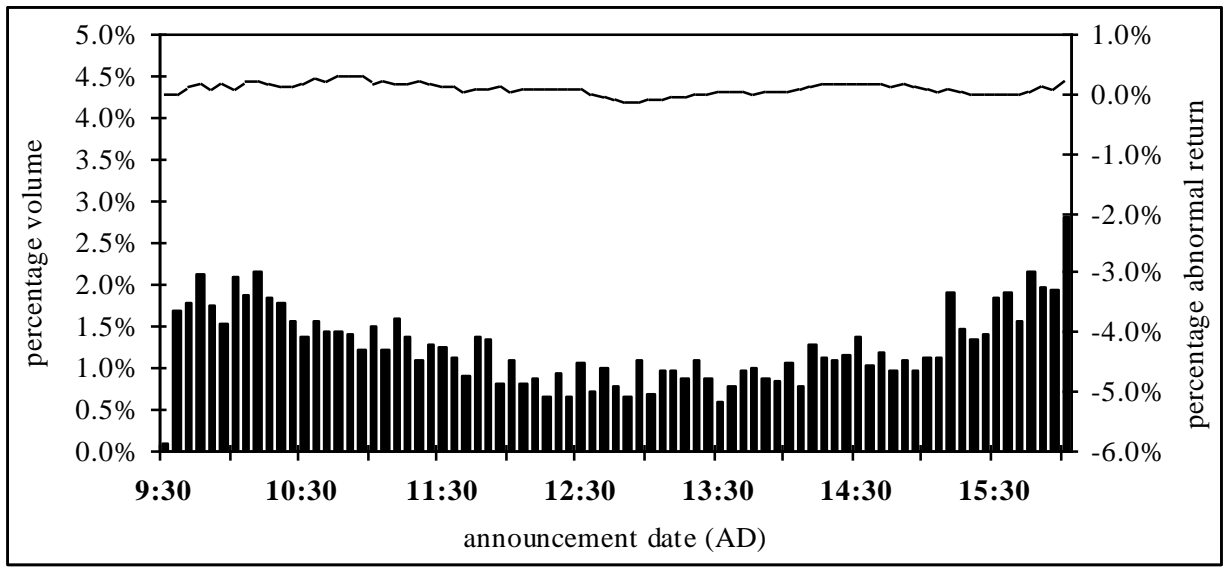

Figure 2: Cumulative abnormal performance and number of shares traded over each five-minute interval expressed as a percentage of the total daily volume of the average added stock on $\mathrm{AD}+1$

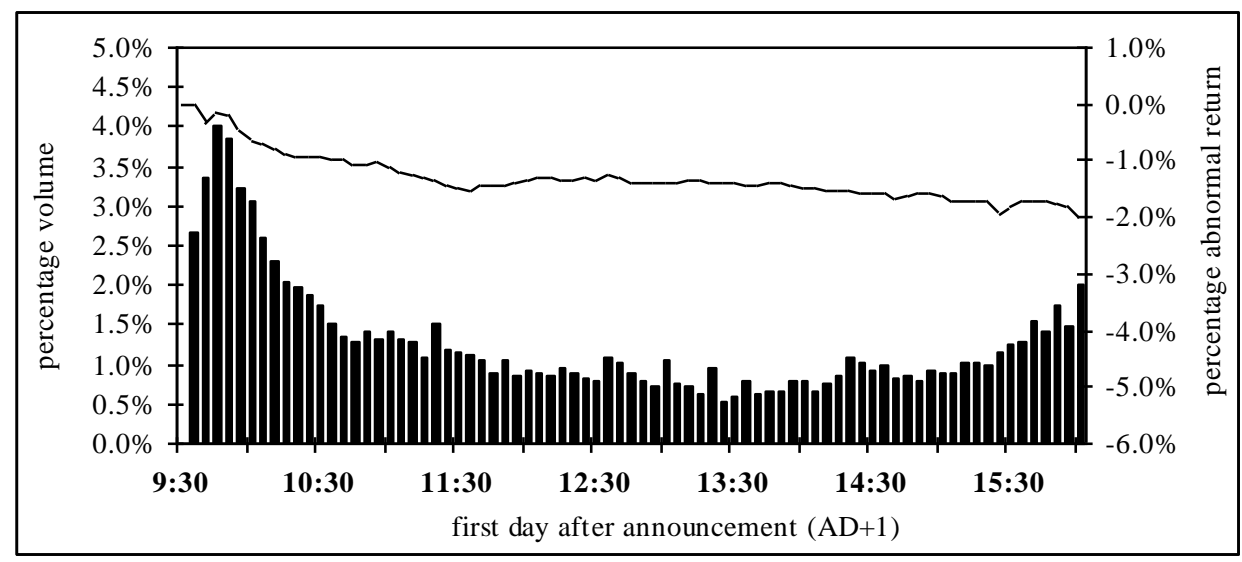

Figure 3: Tick-by-tick cumulative abnormal performance of the average NASDAQ vs. NYSE added stock on AD+1

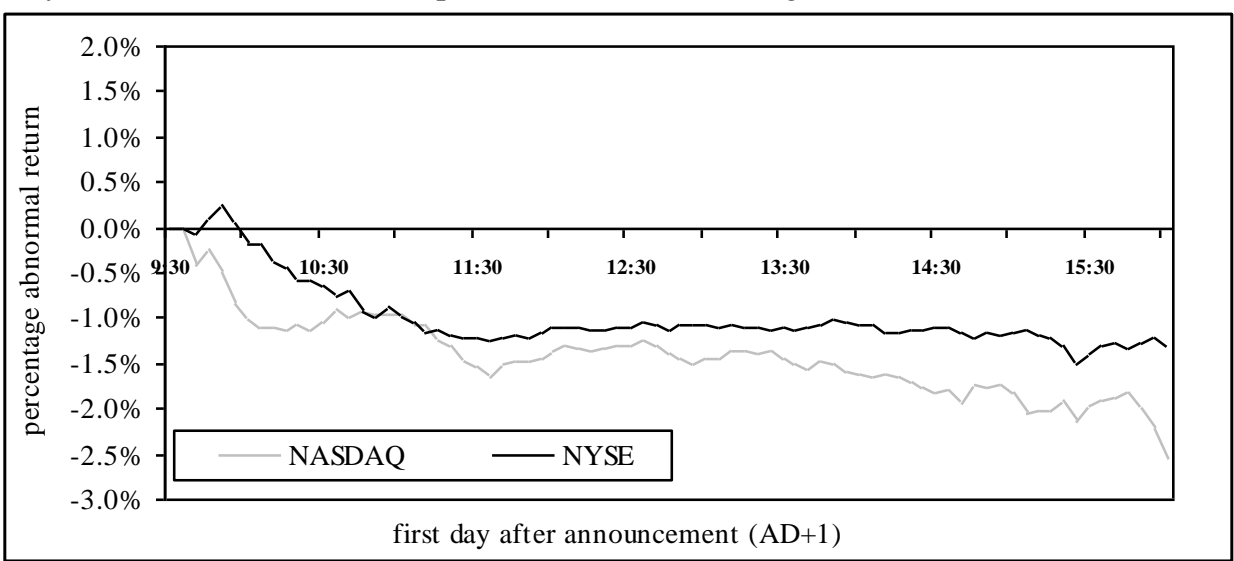


Figure 4: Cumulative abnormal performance of the average added stock and number of shares traded over each five-minute interval expressed as a percentage of the total daily volume on ED

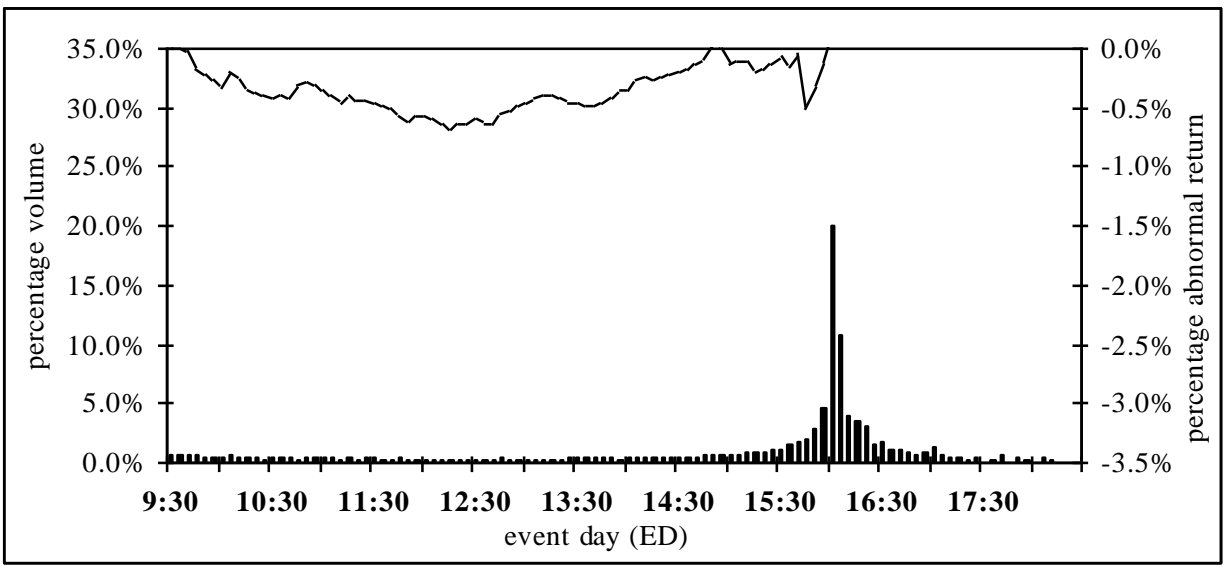

Figure 5: Tick-by-tick cumulative abnormal performance of the average NASDAQ vs. NYSE added stock on the ED

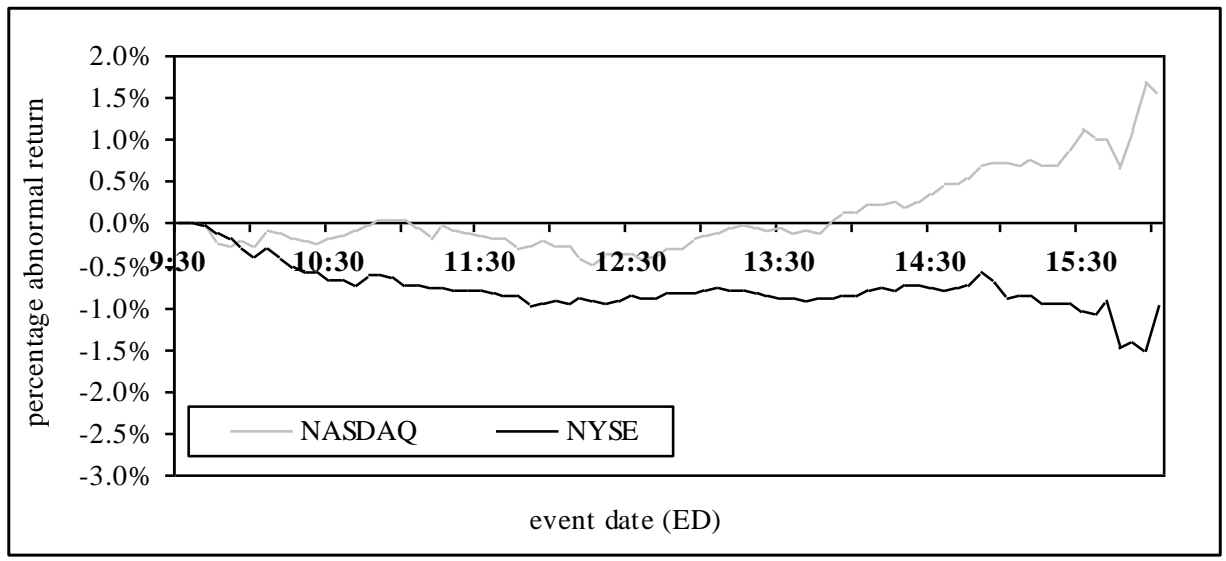

Figure 6: Tick-by-tick average cumulative firm abnormal performance of the average added stock and number of shares traded over each five-minute interval expressed as a percentage of the total daily volume on ED+1

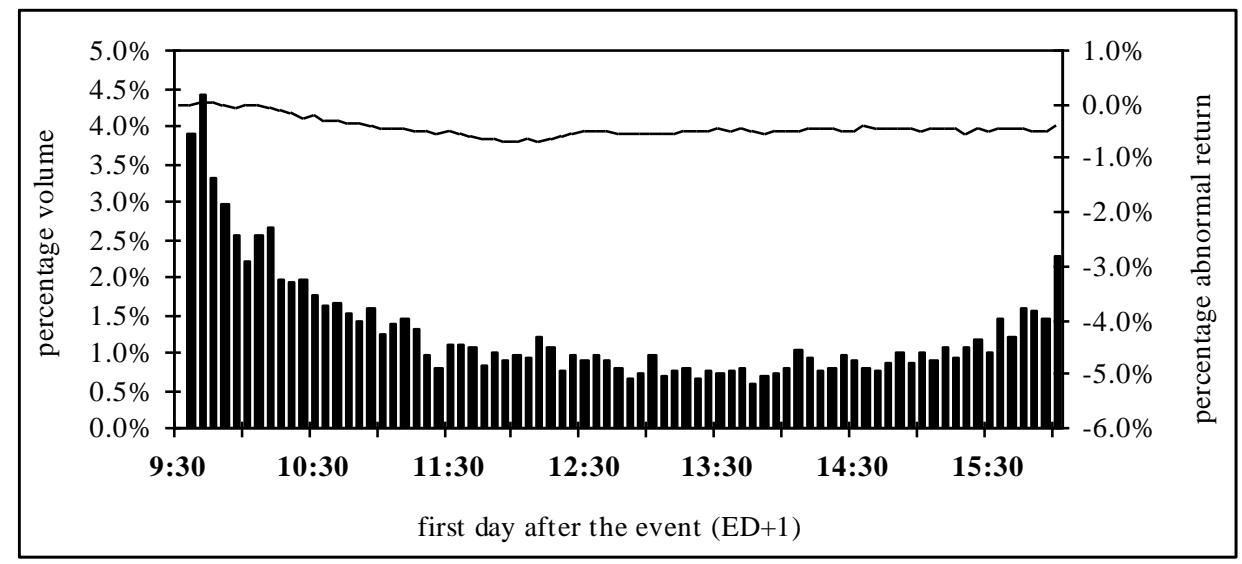


Figure 7: Intraday cumulative abnormal return and trading volume at 5-minute intervals for the deletions sample on ED

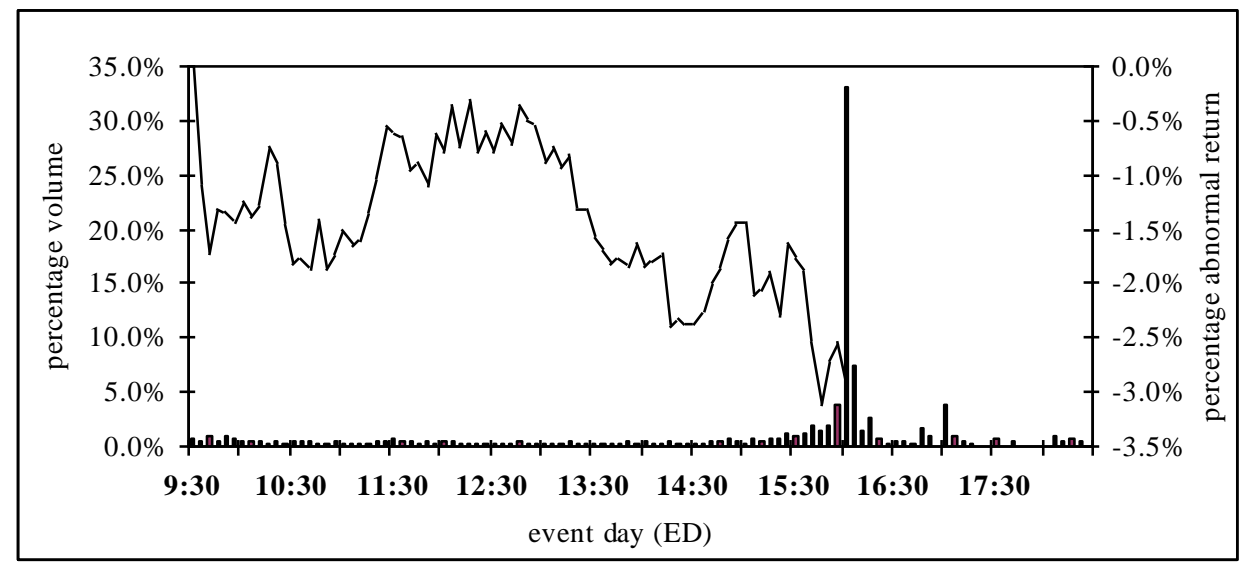

